\title{
Editorial: What Philosophy Is
}

With the explosion of courses in the ethics of various fields, medical, managerial, environmental and so on, the question of the nature of the philosophical enterprise is once again a live topic. $M$ aybe as a result of sensitivity to accusations of bias and preaching in the way individual philosophers might teach these courses, the supposedly discredited conceptual analysis view is once again gaining adherents. Philosophers ought to clarify concepts and commitments, but they ought not to argue for particular concepts or commitments. When they do, they exceed their brief as philosophers, and become proponents of particular causes and world-views. And this is unprofessional, not to be tolerated in the academy.

At the same time the view once espoused by Russell has never gone entirely out of fashion. Philosophy is the name given for those bits of knowledge which cannot (yet) be fitted into pigeon holes like those containing mathematics, psychology, physics and the rest. But, as with natural philosophy in the middle ages and psychology in the nineteenth century, things move on. Earlier we got physics and psychology. $\mathrm{N}$ ow, in a similar spirit of intellectual house-cleaning, chunks of political philosophy are hived off to political science, bits of moral philosophy become jurisprudence, and the new philosophy of mind transforms itself into cognitive science.

$\mathrm{Much}$ of this is doubtless a consequence of the specialization endemic to academic life, with its resulting turf wars and empire building. But what underlies both this purported cutting off of disciplines from their philosophical roots and conceptual analysis is an impoverished view of philosophy and of human activity more generally. It is just not possible to separate evaluation from analysis, philosophical world-view from one's approach to particular sciences and specialisms.

When R yle clarified the concept of mind, he was not simply mapping conceptual geography. H e was arguing powerfully for a particular position, and-despite surface appearance-one replete with evaluation and ontological commitment. And similar things could be said for Popper's description of the open society, Rawls' account of justice and Strawson's analysis of individuals, to say nothing of L ocke's account of the distinction between primary and secondary qualities, $\mathrm{K}$ ant's analysis of moral reasoning or A ristotle's account of substance.

It is idle to pretend that conceptual analysis will not reflect all kinds of commitments and evaluations on the part of the analyst. It 


\section{Editorial}

is also idle to pretend that one can do subjects like physics, psychology, sociology, jurisprudence or cognitive science without hosts of philosophical views. It is just not possible to shove philosophy into an evaluative limbo or to keep philosophy out of the other pigeon holes of academia. $\mathrm{N}$ or would either of these things be desirable if one believes that in doing philosophy one is responding to fundamental human concerns, wherever they arise.

What is undesirable is not that in pursuing their philosophical commitments philosophers should be guided by their fundamental commitments. What is undesirable is the pretence that it is possible to do philosophy without fundamental commitments. 